\title{
O QUE TEM A NOS ENSINAR O PROCESSO DE GERMINAÇÃO DO FEIJÃO?
}

\section{What has to teach us the bean germination process?}

\author{
Roque Ismael da Costa Güllich (bioroque.girua@gmail.com) ${ }^{1}$ \\ Universidade Federal da Fronteira Sul - UFFS
}

\begin{abstract}
Resumo: Este relato de experiência é uma história narrada com a finalidade de apresentar à discussão pública ideias de Investigação e Pesquisa como propostas que dão assentamento ao Ensino de Ciências, como forma de desenvolvimento da Didática no Ensino Superior no que concerne a formação de novos professores de Ciências (Biológicas). Para tanto, tomo como referência um conjunto de aulas sobre a germinação do feijão desenvolvidas no componente curricular de Prática de Ensino sobre currículo e o ensino de Ciências, do Curso de Ciências Biológicas, da Universidade Federal da Fronteira Sul - UFFS, Campus Cerro Largo, Estado do Rio Grande do Sul - RS, Brasil - BR, que são desenvolvidas tendo como espaço e tempo de ampliação um facegrupo do Facebook. A partir da experiência refletida tenciono o conceito de experimentação investigativa e contextual para avançar nas necessidades da investigação no ensino de Ciências, como aposta principal da qual decorrer $o$ desenvolvimento profissional docente dos futuros professores, ao passo que também me coloco também como professor que aprende e ensina a ensinar, em meio às dificuldades que a docência em tempos contemporâneos nos impõe.
\end{abstract}

Palavras-chave: Ensino por investigação, Educar pela Pesquisa, Formação de Professores, Ensino Superior, Facebook.

\begin{abstract}
This experience report is a story narrated with the purpose of presenting to the public discussion Research and Research ideas as proposals that support Science Teaching, as a way of developing Didactics in Higher Education regarding the formation of new Science teachers. (Biological). To this end, I take as a reference a set of bean germination classes developed in the Curriculum component of Teaching

\footnotetext{
${ }^{1}$ Professor Adjunto de Prática de Ensino e Estágio Supervisionado em Ciências e Biologia da UFFS. Pesquisador Líder do Grupo de Estudo e Pesquisa em Ensino de Ciências e Matemática GEPECIEM/CNPq/UFFS. Tutor do PETCiências/UFFS, bolsista MEC-SESu/FNDE.Coordendaor do Programa de Pós-graduação em Ensino de Ciências (PPGEC) - UFFS/CAPES.
} 


\section{Vol. 2, n. 3 - Edição Especial: Ciclos Formativos em Ensino de Ciências.}

Practice on curriculum and science teaching, from the Biological Sciences Course, Federal University of Soufh Frontier - UFFS, Campus Cerro Largo, State of Rio Grande do Sul - RS, Brazil - BR, which are developed with the space and time of expansion of a Facebook group. From the reflected experience I intend the concept of investigative and contextual experimentation to advance the needs of research in science education, as the main bet from which to develop the professional development of future teachers, while also putting myself as a teacher who learns and teaches to teach, amid the difficulties that teaching in contemporary times imposes on us.

Key words: Teaching by research, Educate by Research, Teacher Education, Higher Education, Facebook.

\section{Introduzindo a temática}

"a ocasião é que faz o ladrão"2

Formar professores em tempos contemporâneos tem lá suas dificuldades, ora é o celular na mão, ora são os infindáveis bate-papos de corredor ou sala de aula a atrapalhar a boa execução dos planejamentos. Estes (des)caminhos da juventude contemporânea afetam atualmente não somente a Educação Básica, por certo também a Educação Superior e desse modo, apresentam-se questões e dilemas que enfrento na nos processos de docência tais como: como formar novos professores de Ciências(Biológicas) com contextos de contramão? De que maneira refletir sobre o processo de constituição docente e ao mesmo tempo comprometê-los com a formação e docência?

Entre tantos questionamentos que circulam meu processo de planejar-ensinarrefletir, estava também no ano 2017 a tarefa de pensar processos de ensino e de aprendizagem para 57 licenciandos de Ciências(Biológicas) no período que lecionava a Prática de Ensino em Ciências/Biologia II: Currículo no Ensino de Ciências e Biologia superassem a ideia de um ensino de Ciências(Biológicas) livresco baseado no uso

\footnotetext{
${ }^{2}$ Ditado popular recolhido da linguagem cotidiana.
} 


\section{Vol. 2, n. 3 - Edição Especial: Ciclos Formativos em Ensino de Ciências.}

exclusivo deste material pedagógico por professores da área (GERALDI, 1993; KRASILCHICK, 2004; GÜLLICH, 2013) e a ideia de ciência reproducionista pode ser explicada pelo fato de que neste: "as experiências [experimentos e práticas] somente são exercidas pela cópia, que comanda o ensino e acaba por instituir e reforçar uma visão de ciência neutra, verdadeira e empírico-positivista que também reforça a imagem de Ciência estática que reproduz o conhecimento e não o cria, o recria e o transforma" (GÜLLICH, 2004, p. 5; GÜLLICH; SILVA, 2013).

Entre outros aspectos circulantes no processo que apresento para reflexão neste relato estavam as questões teórico-metodológicas que envolvem o Educar pela Pesquisa e o Ensino por Investigação como perspectivas basilares para formação crítica em Ciências (ver Quadro 1), tomadas aqui como perspectivas que se complementaram no processo de ensino investigado.

Quadro 1: Apresentação das perspectivas de ensino tomadas como referência

\begin{tabular}{|c|c|c|}
\hline $\begin{array}{c}\text { Metodologias de } \\
\text { ensino }\end{array}$ & Educar pela pesquisa & Ensino por investigação \\
\hline $\begin{array}{ll}\text { Sínteses } & \text { das } \\
\text { Metodologias } & \end{array}$ & $\begin{array}{l}\text { A pesquisa } \\
\text { em sala de aula, } \\
\text { como estratégia de } \\
\text { ensino, constitui-se } \\
\text { como um } \\
\text { movimento } \\
\text { dialético, em espiral, } \\
\text { que se inicia com o } \\
\text { questionar dos } \\
\text { estados do ser, } \\
\text { fazer, e conhecer, } \\
\text { possibilitando } \\
\text { construir-se novos } \\
\text { argumentos que } \\
\text { possibilitem atingir } \\
\text { novos patamares } \\
\text { deste ser, fazer e } \\
\text { conhecer, estágios } \\
\text { estes então } \\
\text { comunicados a } \\
\text { posteriori }\end{array}$ & $\begin{array}{l}\text { A situação problema é } \\
\text { apresentada aos alunos, a partir da } \\
\text { leitura do enunciado do problema, da } \\
\text { identificação e do debate das questões } \\
\text { propostas, e esclarecimento de termos } \\
\text { desconhecidos e demais dúvidas. } \\
\text { Depois, estimulam-se os alunos para } \\
\text { buscarem identificar questões } \\
\text { específicas contidas no problema, nesta } \\
\text { etapa os alunos devem propor } \\
\text { hipóteses explicativas. Dando } \\
\text { continuidade, são realizados estudos } \\
\text { afins de testar as hipóteses propostas e } \\
\text { construir novos conhecimentos que } \\
\text { permitam alcançar os objetivos de } \\
\text { aprendizagem. Feito isso, o problema e } \\
\text { as possíveis soluções são (re)discutidos } \\
\text { em sala de aula, no grande grupo, e com } \\
\text { a participação de todos os alunos faz-se } \\
\text { uma análise das hipóteses construídas, } \\
\text { refutando-se as necessárias com base }\end{array}$ \\
\hline
\end{tabular}


Vol. 2, n. 3 - Edição Especial: Ciclos Formativos em Ensino de Ciências.

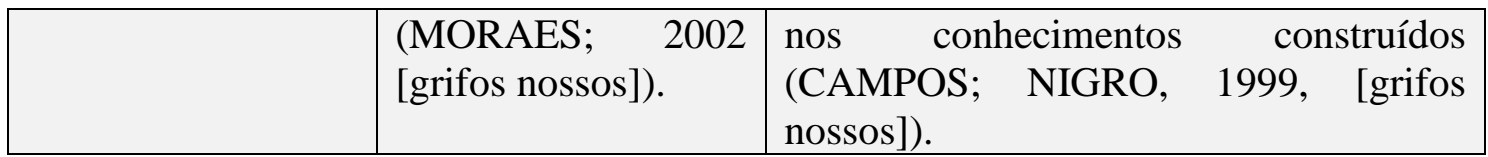

Fonte: Adaptado de Boszko e Güllich, 2016.

Aforante a ementa do componente e tendo claro o objetivo de formar novos professores da área, no início do semestre surgiu uma questão intrigante que fez com que meu planejamento sofresse grandes e significativas alterações, uma vez que acredito que é "a ocasião que faz o ladrão", então surgindo a ocasião, aproveitei a oportunidade. É sobre parte delas e como este processo desencadeou a possibilidade/oportunidade de ensinar pela pesquisa e desenvolver um ensino por investigação que irei desenvolver esta narrativa-relato, a fim de apresentar a proposta desenvolvida, melhor compreendê-la e explicitar os dilemas práticos que surgiram no processo como problemas de investigação da minha própria prática/docência como professor formador na Educação Superior.

\section{Contextualizando a ação pedagógica}

"feio não é roubar, feio é roubar e não poder carregar"3

Nas aulas de prática de ensino sobre currículo e o ensino de Ciências e Biologia, do Curso de Ciências Biológicas - Licenciatura, que tem por objetivo formar novos professores a partir da discussão de diferentes metodologias de ensino, surgiram questões que pareciam muito simples: Como ocorre a germinação do feijão? E, o que nasce primeiro a plântula ou a radícula? Partindo desta problemática inicial, que os licenciandos não sabiam responder a priori, desenvolvemos um processo de ensino por investigação, pois "feio não é roubar, feio é roubar e não saber carregar" é quase que uma tradução alinhada ao "de um limão fazer a limonada", pois ao me deparar com as questões que os alunos desconheciam fazendo Ciências Biológicas, resolvi roubar a

\footnotetext{
${ }^{3}$ Ditado popular recolhido do cotidiano, sendo que este em especial era recitado por uma tia avó, da parte de minha mãe para explicar coisas da vida, como o rapaz que roubou a namorada, mas a perdeu, como as pessoas que roubavam coisas e as desperdiçavam (tipo milho verde em beira de estrada), naquela época tenho clareza que não entendia o verdadeiro sentido deste "roubar" e achava até estranho.
} 


\section{Vol. 2, n. 3 - Edição Especial: Ciclos Formativos em Ensino de Ciências.}

cena, replanejar, mudar o conteúdo das aulas e redimensionar a discussão em torno do currículo e suas teorias, para o currículo vivo em contraposição a ideia de ensino livresco, bem como da ciência copiada já apresentadas na introdução, e foi assim que procedi roubando da minha estrutura geral planejada e sabendo carregar a discussão para o processo de formação intencionada.

O processo de ensino e aprendizagem da metodologia de ensino por investigação, bem como do processo de germinação deu-se mutuamente, pois enquanto pesquisavam e aprendiam sobre o processo de germinação, também aprendiam uma metodologia de ensinar Ciências. A prática que está aqui relatada ocorreu durante um conjunto de aulas que duraram 21dias, ministrada para 57 alunos da turma de 2017-1, do Curso de Ciências Biológicas, da Universidade Federal da Fronteira Sul - UFFS, Campus Cerro Largo, Estado do Rio Grande do Sul - RS, Brasil - BR.

Inicialmente solicitei que, em grupos de 5 integrantes plantassem 7 feijões de feira em uma garrafa pet cortada longitudinalmente preenchida com solo fértil, todos lado a lado, sendo um a cada dia e que fotografassem todos os dias postando as fotos no facegrupo do Facebook ${ }^{4}$ da turma, sendo todas as fotos, como comentários da postagem de cada grupo. No decorrer dos dias acidentes que aconteceram nas rotinas das casas fizeram com que ao $4^{\circ}$ dia fossem expostas sementes de um dos experimentos, tornando visível, a radícula em desenvolvimento em uma das sementes.

$\mathrm{Na}$ semana seguinte todos os grupos trouxeram para sala de aula os experimentos com feijões germinados, feijões em crescimentos, feijões não germinados e feijões em processo de germinação aparente, nesta aula foram levados a responder uma série de questões:1- O que surgiu antes no solo?; 2- O que surgiu antes na semente; 3- Que fatores influenciaram a germinação; 4- como faziam essa experiência em sua escola? 5- Que conteúdos podem ser trabalhados com o experimento além da germinação?; 6- O que você faria com o atual experimento?', desenvolvidas em aula e

\footnotetext{
${ }^{4}$ Tenho utilizado a rede social Facebook, com base nos estudos de Lorenzo (2013) e de Porto e Santos
} (2017) sobre o uso das redes sociais na educação. 


\section{Vol. 2, n. 3 - Edição Especial: Ciclos Formativos em Ensino de Ciências.}

em grupos para pensar, analisar e rever as possíveis discussões envolvidas no trabalho investigativo que poderiam fazer em sala de aula com alunos e que eles mesmos pudessem pensar como alunos do Curso de C. Biológicas. As respostas geraram discussão em sala de aula e foram sendo registradas no quadro pelo professor. Nesta aula cada grupo recebeu também um texto acadêmico de ensino de Ciências sobre germinação, a fim de favorecer a problematização do tema e abordagem pedagógica do conteúdo, texto que favoreceu outras discussões mais aprofundadas, bem como o registro escrito feito em diário de formação ${ }^{5}$ durante todo o processo como parte do desenvolvimento individual de cada professor em formação.

Após esta aula encaminhei uma pesquisa exploratória em diferentes fontes, sendo cada grupo responsável por um campo de exploração de dados/informações buscando argumentos para a produção de conhecimentos científicos, entrevistando: alunos formandos de Ciências Biológicas; - alunos formandos de Agronomia; professor de Botânica de C. Biológicas; - professor de fisiologia vegetal Agrônomo, compondo o campo de experts, e pesquisando: - artigos de periódicos de pesquisa em ensino de ciências; - artigos de periódicos de relatos de experiências de ensino de ciências; - relatos de experiências no evento como o Encontro Investigação na Escola; Google acadêmico e no - Scielo, para que cada grupo elaborasse um vídeo explicativo sobre o processo de germinação contendo suas elaborações coletivas sobre o processo, este vídeo deveria ser postado no Facebook da turma para que todos tivessem acesso, num prazo de mais 15 dias.

Por este mesmo prazo alguns grupos selecionados postaram fotos dos feijões que cresceram e estes foram sendo acompanhados de discussões sobre o crescimento das plantas, luz, solo e interações ecológicas que surgiram nos exemplares que eram assim investigados.

\footnotetext{
5 Nas práticas de ensino do Curso de Ciências Biológicas nos utilizamos do diário de formação, na acepção de Porlán e Martín (2001), como forma de desenvolvermos narrativas de formação que dão espaço e tempo de formação pela investigação de concepções e práticas docentes permitindo focalizar o processo de constituição docentes e guardando também a história da própria formação do professor.
} 


\section{Vol. 2, n. 3 - Edição Especial: Ciclos Formativos em Ensino de Ciências.}

\section{Proposição: $O$ ensino com investigação/pesquisa facilita a aprendizagem em} Ciências e a formação de novos professores

"na prática, a teoria é outra"6

Os vídeos criados (Figura 1) foram bem organizados e demonstraram a investigação empírica e teórica de cada grupo. Acredito que todo o processo favoreceu o desenvolvimento de conhecimentos técnicos-científicos, pedagógicos, tecnológicos e atitudinais entre professores em formação, pelo que também creio ter ensaiado com meus alunos como se ensina por investigação/com pesquisa nas aulas de Ciências (Biológicas).

Figura 1: Vídeos do processo de germinação da Experimentação à Investigação

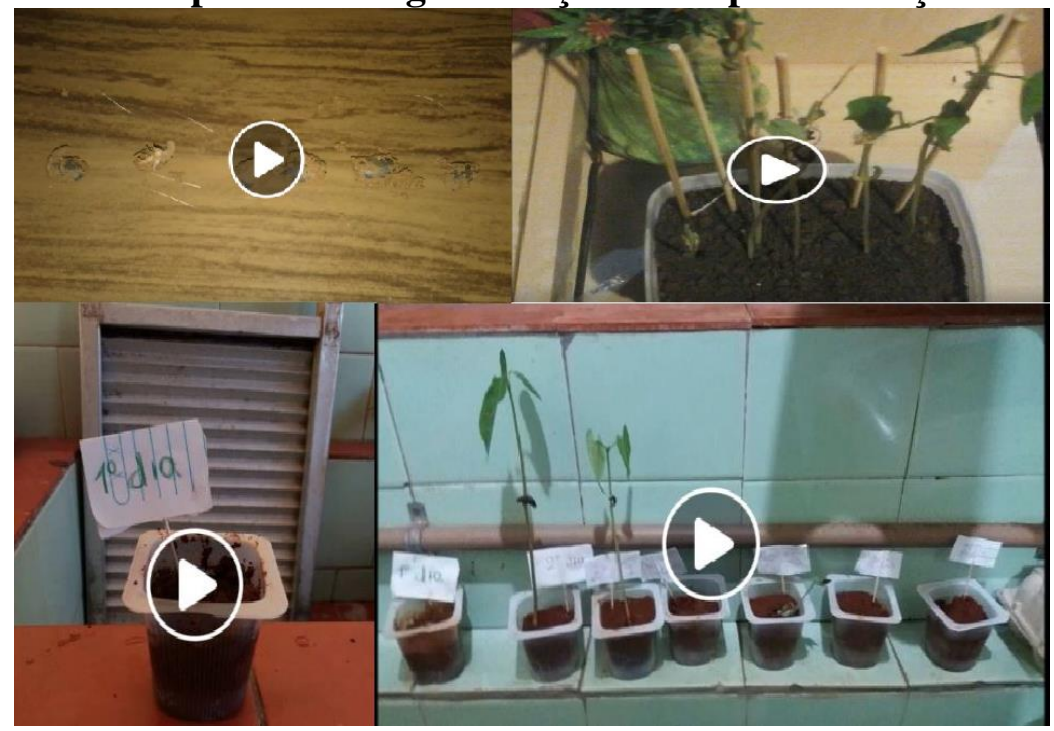

Fonte: Facegrupo, 2017-1. Nota: Prática de Ensino: Didática e metodologia de Ciências e Biologia.

A dimensão imagética/tecnológica que as fotos do processo (Figura 2) e os vídeos construídos apresentam são importantes na mediação das aprendizagens, pois os

\footnotetext{
${ }^{6}$ Apologia a uma certa balbúrdia que sempre ouvimos, de que na prática a teoria é outra, utilizada justamente para suprimir a ideia de que necessitamos de teoria para examinar as práticas, ideia da qual discordo completamente.
} 
evista Insignare Scientia

\section{Vol. 2, n. 3 - Edição Especial: Ciclos Formativos em Ensino de Ciências.}

licenciandos a medida que desenvolviam a ação também postavam no grupo da turma fotos dia por dia do processo de germinação permitindo ao professor e a turma de um lado acompanhar de cada grupo o processo desenvolvido; de outro expandir a sala de aula para casa e para os contextos com o uso da redes social, neste caso o Facebook como defendem Porto e Santos (2017). Esta dimensão também permitiu a ampliação e significação conceitual dos licenciandos envolvidos no processo.

Figura 2: Fotos do processo de Germinação do Plantio até as interações ecológicas

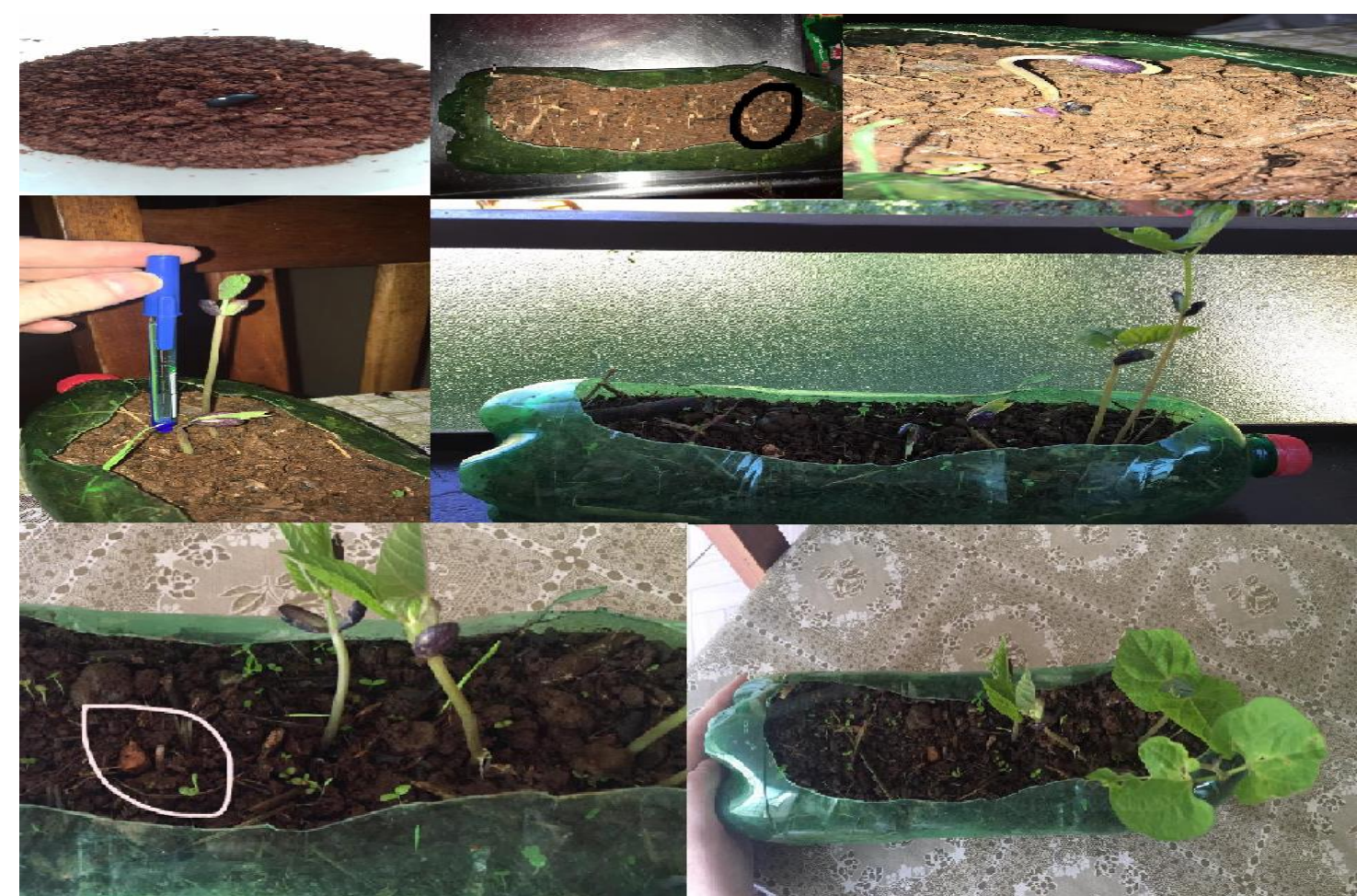

Fonte: Facegrupo, 2017-1. Nota: Prática de Ensino: Didática e metodologia de Ciências e Biologia.

Já a dimensão teórico-metodológica foi sendo reelaborada por dois caminhos, um que passa pela pesquisa exploratória dada pelas leituras, buscas ativas em referências, sites e entrevistas com especialistas(ideia do educar pela pesquisa de MORAES, 2002), desenvolvimento do experimento de germinação (ideia do ensino por investigação de CAMPOS; NIGRO, 1999) que favoreceram a significação conceitual e a estruturação do vídeo final que explicita a germinação do feijão na visão de cada 


\title{
Vol. 2, n. 3 - Edição Especial: Ciclos Formativos em Ensino de Ciências.
}

grupo, bem como pelo exercício de pensar a estratégia didática que aprendiam(os licenciandos) como futuros professores de Ciências(Biológicas), pois concordando com Castro e Carvalho (2001) é necessário ensinar a ensinar as novas gerações de professores, no que também podemos reforçar a tese que tenho defendido de que para bem aprender é preciso bem ensinar (GÜLLICH, 2017). Pelo que também aponto aspectos não destacados no relato como a avaliação das aprendizagens, sobre o qual defendo um processo de avaliação formativa (GÜLLICH, 2013), na ideia de que todas as atividades desenvolvidas são avaliadas e geram produtos de avaliação ao longo da ação.

Outro caminho da dimensão teórico-metodológica passa pela abordagem do ensino experimental ou melhor, do que seja experimentação no ensino de Ciências (Biológicas) que nos interessa também discutir. Cabe destacar, que o processo experienciado permitiu circular novas ideias e teorias para sustentar a experimentação sobre a germinação do feijão advindas de outras perspectivas como a investigativa defendida por Motta et al. (2013, p. 2):

\begin{abstract}
a organização da experimentação investigativa na escola envolve trabalhar a partir de perguntas dos alunos e professor sobre os fenômenos da natureza em estudo. Essas perguntas oportunizam a construção de objetos aperfeiçoáveis, que trazem neles modelos de funcionamento desses objetos, o que possibilita questionamentos e argumentos que podem levar a melhor compreender o fenômeno e, com isso, aperfeiçoar este objeto produzido.
\end{abstract}

Considerando que a experimentação[e o ensino], se mediada, organizada e planejada de maneira apropriada, desencadeia um verdadeiro processo de investigaçãoreflexão, trazendo à tona as hipóteses levantadas e sugeridas ao longo do processo, sendo que para se fazer uma experimentação investigativa, além dos critérios já citados, deve-se fazer presente também perguntas que instigam a reflexão e o fomento pela pesquisa por parte dos alunos, e além disso, deve-se levar em consideração os questionamentos e argumentos dos mesmos para com o objeto estudado, para assim, se obter a melhor compreensão possível do fenômeno. Ou seja, o que garante a 


\title{
Vol. 2, n. 3 - Edição Especial: Ciclos Formativos em Ensino de Ciências.
}

aprendizagem é a interação entre os sujeitos, sendo esta mediada pelo diálogo, na argumentação, na discussão dos resultados, enfim, na troca de saberes entre todos os alunos mediada pelo professor (GÜLLICH; WALCZAK; MATTOS, 2016; WALCZAK; MATTOS; GÜLLICH, 2017).

Acreditamos com base em estudos de Wyzykowski; Güllich; Araújo (2016) e de Bremm; Güllich (2019) que a experimentação e o ensino de Ciências precisam ser de caráter contextual como também fica reforçado no excerto:

\begin{abstract}
nessa concepção [contextual], para que as atividades práticas surtam efeito no processo de ensino e aprendizagem e tornem-se um meio viável para ensinar Ciências, alguns elementos devem ser levados em consideração para desenvolvê-las, tais como: unir a teoria e a prática de modo que ambas dialoguem; pensar a importância do planejamento dessas aulas, bem como a contextualização do tema; primar por questionamentos durante o experimento que propiciem interações verbais entre os sujeitos de modo a ser produzido um diálogo formativo e conceitual; destinar um tempo posterior à atividade para a discussão com os alunos; solicitar ao grupo a produção de relatórios para diagnóstico da compreensão dos conteúdos/conceitos abordados e, por fim; é indispensável à reflexão do professor sobre o processo a fim de que possa investigar sua prática. É por meio da sistematização/pesquisa das práticas, com o hábito da reflexão, que podem ser produzidos novos significados à experimentação por isso é muito importante que o professor reflita sobre seus procedimentos de ensino (WYZYKOWSKI; GÜLLICH, 2012, p. 6).
\end{abstract}

Temos discutido e acreditado que a “[...] experimentação não deve ser apenas de cunho investigativo, ela deve ser investigativa e o licenciando deve a conceber de forma contextual". Ou seja, além dele fazer uso da metodologia descrita neste relato, "ele também deve fazer uso da reflexão crítica acerca do experimento em questão" (BREMM; GULLICH, 2018, p. 8).

As referências de Moraes (2002) e Campos e Nigro (1999) tomadas como pontapé inicial deste estudo, favorecem o desenho metodológico que acreditamos ter praticado neste contexto investigado e dão margem para defesa de um novo sentido, que parte das ações envolvidas com experimentos contextuais-investigativos e dão margem a pensar a centralidade da investigação/pesquisa no Ensino de Ciências. Neste sentido, extrapolamos o ensino por experimentação e recolocamos a dimensão do que seja a 


\section{Vol. 2, n. 3 - Edição Especial: Ciclos Formativos em Ensino de Ciências.}

defesa da investigação/pesquisa no ensino de Ciências (Biológicas), como um elemento central, o ensino de Ciências precisa decorrer da investigação/pesquisa, e esta precisa levar em conta o contexto em seu caráter investigativo.

Carr e Kemmis (1988) em suas defesas pela investigação-ação como teoria de formação dos professores e teoria de educação crítica defendem que os referenciais precisam ser também pervertidos/transformados colocados em xeque e prova, abandonados e refeitos, defendem inclusive que a investigação-ação crítica deve ser também teórica, mas sobretudo prática! É com base neste argumento que defendi nesta análise algo mais teórico do modelo de Ensino por Investigação ou pela Pesquisa, no que também adianto de que na minha versão do "na prática a teoria é outra" que cada um o chame (o modelo aqui discutido) como quiser e bem entender, mas sobretudo o defenda, aplique, replique, questione, condene, reforce, transmute, pois é quando estamos em movimento que aprendemos já nos avisou um grande autor russo. Destaco que os modelos teórico-metodológicos precisam ser melhor investigados e que não há melhor forma de fazê-lo a não ser fazendo, no que serviria afirmar: menos crítica, mais prática.

\section{Ensinar e aprender por investigação: retomando as memórias e questões iniciais}

"água mole pedra dura, tanto bate até que termina a água"7

Afinal, porque mesmo resolvi narrar esta história? Haviam aspectos já discutidos nos resultados que se deram em torno do aspecto teórico-metodológico de ensinar a ensinar por investigação, porém revisitando minhas memórias e as questões inicias lembro-me que estava difícil ensinar aos professores em formação em 2017-1, ao que os licenciandos de Ciências (Biológicas) da época me pareciam intransigentes, hiperativos,

\footnotetext{
${ }^{7}$ Ditado popular recolhido do cotidiano.
} 


\section{Vol. 2, n. 3 - Edição Especial: Ciclos Formativos em Ensino de Ciências.}

bagunceiros, descolados - pera aí, tudo isso? Sim, tudo e mais um pouco, mas um tanto quanto como eu, e confesso aqui!

Mas, é importante frisar que eles respondiam, davam retorno, se empolgavam, incomodaram-se comigo quase na mesma medida de que eu incomodei-me com eles, e creio que este movimento de ser professor e do desejo de ensinar, causou um efeito de corresponsabilidade(num sentido Bakhtiniano) que num exercício de docência e loucura $^{8}$ me fez embarcar em novas proposições. Pude perceber com o processo que o Facebook os deixaria mais a vontade para aprender, que a investigação poderia tornar as aulas mais atrativas e participativas, que o movimento de ir e vir das práticas às teorias era necessário naquele momento e então ao final do semestre os medos e as ousadias se converteram em muitas aprendizagens conceituais, metodológicas e da constituição dos sujeitos professores (num sentido Vigotskiniano).

Para finalizar, não poderia deixar de tocar num ditado popular, escolhi adaptar o tradicional: "água mole pedra dura, tanto bate até que fura”, para: "até que termina a água”, pois precisamos urgentemente romper paradigmas antes que água ou tempo termine, romper concepções de docência, práticas de ensino, processos de formação, romper e transgredir para redesenharmos teorias, modelos e novas práticas que quiçá causem a transformação na Universidade e na Escola, na formação e nas aulas de Ciências e só assim, melhorias sociais.

\section{Referências}

BOSZKO, C.; GÜLLICH, R.I.C. O desenvolvimento do pensamento crítico em ciências: um ensaio comparativo entre estratégias de ensino em contexto brasileiro. Revista de Ensino de Biologia - REnBio, SBEnBio, Niterói-RJ. v.9, n.9, p. 29913003, 2016.

\footnotetext{
${ }^{8}$ Escrevi loucura porque por muitos dias, muitos deles me enlouqueceram, fizeram-me até mesmo comprar um relógio para não usar o telefone.
} 


\section{Vol. 2, n. 3 - Edição Especial: Ciclos Formativos em Ensino de Ciências.}

BREMM, D.; GÜLLICH, R. Dos cheiros às memórias da escola: Formação e docência em Ciências Biológicas. Contexto \& Educação, Vol. 33, n. 106, p. 254-270, 2018.

BREMM, Daniele; GULLICH, Roque Ismael da Costa. Concepções sobre experimentação na formação inicial de professores de ciências. In : FERREIRA, Eric Duarte; STARIKOFF, Karina Ramirez; GULLICH, Roque Ismael da Costa (Orgs.) As experiências formativas do Programa de Educação Tutorial na Universidade Federal da Fronteira Sul. Bagé: Faith, 2019. p. 95-98.

CAMPOS, M. C. C.; NIGRO, R. G. Didática de ciências: o ensino-aprendizagem como investigação. São Paulo: FTD, 1999.

CARVAlHO, A. M. P. de; GIL-PÉREZ, Daniel. Formação de professores de ciências. São Paulo: Cortez, 2000. 120p.

CARR, W.; KEMMIS, S. Teoria crítica de la enseñanza: investigación-acción en la formación del profesorado. Barcelona: Martinez Roca, 1988.

CASTRO, A. D.; CARVAlHO, A. M. P. (orgs.). Ensinar a Ensinar. São Paulo: Pioneira, 2001.

GERALDI, C. M. G. A produção do ensino e pesquisa na educação: estudo sobre o trabalho docente no curso de pedagogia. Campinas: [s.n.], 1993. (Tese de doutoramento, Unicamp).

GÜLLICH, Roque Ismael da Costa. Desconstruindo a imagem do livro didático no ensino de ciências. Revista SETREM. Três de Maio, v. 4, n. 3, p. 43 - 51, jan. 2004.

GÜLLICH, Roque Ismael da Costa. Investigação-Formação-Ação em Ciências: um caminho para reconstruir a relação entre livro didático, o professor e o ensino. Curitiba: Editora Prismas Ltda, 2013.

GÜLLICH, R. I. S.; SILVA, L. H. A. O enredo da experimentação no livro didático: construção de conhecimentos ou reprodução de teorias e verdades científicas? Ensaio: Pesquisa em Educação em Ciências, Belo Horizonte, vol. 15, n. 2, p. 155-167, 2013. GÜLlICH, R. I. C.; WALCZAK, A.T.; MATTOS, K.C.D. Experimentação 


\section{Vol. 2, n. 3 - Edição Especial: Ciclos Formativos em Ensino de Ciências.}

investigativa nos livros didáticos de Biologia. Revista da SBEnBio. N. 9. p. 392-403, 2016.

GÜLLICH, Roque Ismael da Costa. Formação em Ciências e em Biologias: discutindo requisitos de um processo didático. In: GÜLLICH, R. I. C. HERMEL, E. E. S. (Org.) Didática da Biologia. Curitiba: Appris, 2017. -a, v.1, p. 13-26.

LORENZO, Eder Maia. A Utilização das Redes Sociais na Educação: A Importância das Redes Sociais na Educação. 3 ed. São Paulo: Clube de Autores, 2013.126p.

KRASILCHIK, M. Prática de Ensino de Biologia. São Paulo: EDUSP, 2004.

MORAES, Roque. Educar pela pesquisa: exercício de aprender a aprender. MORAES, Roques; LIMA, Valderez Marina do Rosário. Pesquisa em sala de aula: tendências para a educação em novos tempos. Porto Alegre: EDIPUCRS, 2002.

MOTTA, C. S. et al. Experimentação investigativa: indagação dialógica do objeto aperfeiçoável. In : Atas do IX ENPEC. Águas de Lindóia - SP: ABRAPEC, 2013.

PORLÁN, Rafael; MARTÍN, José. El diário del profesor: um recurso para investigación em el aula. Díada: Sevilla, 2001.

PORTO, C.; SANTOS, E., (orgs). Facebook e educação: publicar, curtir, compartilhar [online]. Campina Grande: EDUEPB, 2014, 445p. Disponível em: http://books.scielo.org. Acesso em: 02 jul. 2017.

WALCZAK, A. T.; MATTOS, K. R. C.; GÜLLICH, R. I. C. O que dizem os livros didáticos de Biologia sobre a experimentação?!.Ensino \& Pesquisa, União da Vitória, v. 15, n. 3, p. 221-237, set./dez, 2017. Disponível em:< http://periodicos.unespar.edu.br/index.php/ensinoepesquisa/article/view/994/pdf_31>.

WYZYKOWSKI, T.; GÜLLICH, R. I. da C. Compreendendo concepções de experimentação no processo de iniciação a docência em ciências. Anais IV ENEBIO e II EREBIO, Goiânia, 2012. (CD-ROM).

WYZYKOWSKI, T.; GÜLLICH, R. I. da C.; ARAÚJO, M. C. P. Compreendendo a experimentação em Ciências: entre o discurso e a prática. Revista de Educación en Biología, v. 19 n. 1, p. 35-53, 2016. 